\title{
Behavioral Traits are Affected by Selective Breeding for Increased Wheel-Running Behavior in Mice
}

\author{
I. Jónás $\cdot$ K. A. Schubert • A. C. Reijne $\cdot$ J. Scholte $\cdot$ \\ T. Garland Jr • M. P. Gerkema $\cdot$ A. J. W. Scheurink \\ C. Nyakas • G. van Dijk
}

Received: 21 September 2009/ Accepted: 19 March 2010/Published online: 6 April 2010

(C) The Author(s) 2010. This article is published with open access at Springerlink.com

\begin{abstract}
Voluntary physical activity may be related to personality traits. Here, we investigated these relations in two mouse lines selectively bred for high voluntary wheelrunning behavior and in one non-selected control line. Selection lines were more explorative and "information gathering" in the open-field test, either with increased upright positions or horizontal locomotion toward the middle ring. Furthermore, one of the selection lines had an increased risk-taking behavior relative to the control line in approaching a novel object placed in the center of the open
\end{abstract}

Edited by Stephen Maxson.

I. Jónás · A. C. Reijne · J. Scholte · A. J. W. Scheurink ·

G. van Dijk $(\bowtie)$

Center for Behavior and Neurosciences, Neuroendocrinology

Unit, University of Groningen, Kerklaan 30, 9751 NN Haren,

The Netherlands

e-mail: gertjan.van.dijk@rug.nl

\section{K. A. Schubert}

Center for Behavior and Neurosciences, Behavioral Biology

Unit, University of Groningen, Haren, The Netherlands

T. Garland $\mathrm{Jr}$

Department of Biology, University of California, Riverside, CA, USA

\section{P. Gerkema}

Center for Behavior and Neurosciences, Chronobiology Unit, University of Groningen, Haren, The Netherlands

C. Nyakas

Center for Behavior and Neurosciences, Molecular

Neurobiology Unit, University of Groningen, Haren,

The Netherlands

C. Nyakas

Department of Nutrition and Physical Activity, Semmelweis

University, Budapest, Hungary field. However, anxiety behavior was increased in selection lines during the plus-maze test. Maze learning was not statistically different among lines, but routine behavior was increased in both selection lines when the maze exit after 2 days of testing was displaced. Specifically, in the displaced maze, selected mice traveled more frequently to the old, habituated exit, bypassing the new exit attached to their home cage. Although the generality of the results would need to be confirmed in future studies including all eight lines in the selection experiment, the increased routine and exploratory behavior (at least in the lines used in the present study) may be adaptive to sustain high activity levels.

Keywords Anxiety · Experimental evolution . Maze learning · Open field · Routine behavior . Trait

\section{Introduction}

Much attention has been paid to the mechanisms by which physical activity helps to avoid or ameliorate obesity and associated metabolic derangements (Levin and DunnMeynell 2004; Brock et al. 2005; Patterson and Levin 2008; Hayes and Kriska 2008). In addition, evidence is increasing that physical activity improves mental health (Dey 1994; Dietrich and McDaniel 2004; Hillman et al. 2008). For example, frequent daily performance of exercise, such as endurance running, is able to reduce levels of anxiety and depression (Kligman and Pepin 1992; Antunes et al. 2005), and to augment learning capability in human beings (Hillman et al. 2008). Homologous beneficial effects of physical activity have been demonstrated in rodents on energy balance regulation (Bell et al. 1995; Bi 
et al. 2005), but also on emotionality, stress coping, and learning (van Praag et al. 1999; Rhodes et al. 2003; Greenwood et al. 2007; Pietropaolo et al. 2008).

In a meta-analysis of Rhodes and Smith, it was found that the amount of voluntary or spontaneous physical activity in humans was positively related to such major personality traits as increased extraversion and conscientiousness, and negatively to neuroticism (Rhodes and Smith 2006). A venue not thoroughly explored is the possibility that the display of voluntary physical activity and certain personality traits have common neurobiological or endocrine mechanisms. One approach to investigate whether and how personality traits are associated with the level of spontaneous physical activity is to study homologous behavioral traits in mice from lines that have been selectively bred for high voluntary wheelrunning behavior (Swallow et al. 1998; Garland Jr 2001) and compare these to non-selected control mice. If certain personality traits are related to voluntary physical activity, then one might hypothesize that the expression of homologous behavioral traits is amplified or diminished in mouse lines selected for high voluntary physical activity.

After selective breeding for 16 generations, the four replicate activity-selected lines of mice ran approximately 2.7 times more revolutions in their running wheels per day compared to four non-selected control lines (Swallow et al. 1998), mainly by running at higher speeds rather than more time per day. They also ran more intermittently, with shorter and more-frequent bouts (Koteja et al. 1999; Girard et al. 2001). After locking the wheels, the high-runners spent more time climbing the locked wheels, apparently trying to run (Koteja et al. 1999). When housed in cages without wheels, high-runner mice exhibited elevated homecage activity (Rhodes et al. 2001; Malisch et al. 2008).

Despite a large difference in the level of chronic wheel running behavior between selected and control mice, Rhodes et al. did not observe increased learning in activityselected mice compared to control mice despite increased hippocampal neurogenesis (Rhodes et al. 2003). However, running wheel behavior, learning capability, as well hippocampal neurogenesis were strongly correlated in control runners (Rhodes et al. 2003). Furthermore, Bronikowski et al. did not observe differences in exploratory behavior between selected and control lines in a standard open-field test (Bronikowski et al. 2001). Although these data could be interpreted as evidence against a "behavioral traits hypothesis of voluntary activity", they did, however, find that selected mice displayed fewer turns in their travel paths, which could be indicative of increased motivated behavior in these animals. Finally, selected and control mice differ with respect to stress coping behavior, with the latter showing less behavioral despair during forced swimming (Malisch et al. 2009), and less predatory aggression towards crickets (Gammie et al. 2003).
In the present study, we re-evaluated the hypothesis that mice selectively bred for high voluntary wheel running activity have certain behavioral traits that differ from controls. We tested this hypothesis by analysing a broad spectrum of behaviors, including those that reflect anxiety, exploration, learning, and routine behavior in two activityselected lines and one control line with none of the mice subjected to wheels.

\section{Materials and methods}

Animals

In July-August 2006, mice from generation 45 of the selection experiment for high voluntary wheel running (Swallow et al. 1998) were shipped from The University of California (Riverside, CA) to the University of Groningen (Haren, the Netherlands). Mice used in the present study were offspring of these individuals. For a detailed description of the selection experiment, see (Swallow et al. 1998). In brief, the base population was Hsd:ICR mice, an outbred stock with relatively high levels of genetic variation. In the original selection protocol, eight lines of mice were created ( 4 selected and 4 controls). From this we used male and female mice from two selection lines (lab designations line 7 and line 8) and one control line (line 2). Thus, for simplicity, we did not study selection lines 3 and 6 , both of which exhibit the "mini-muscle" phenotype, caused by a Mendelian recessive allele with many pleiotropic effects (Garland Jr et al. 2002; Hartmann et al. 2008). Because we studied only two selection lines and one control line, the generality of our results would need to be confirmed in future studies of all eight lines in the selection experiment.

For the present study, mice were housed in same-sex groups of two or three per cage, with ad libitum food (Standard lab chow RMH-B 2181, HopeFarms BV, Woerden, NL) and water, at an ambient temperature of $22 \pm 1^{\circ} \mathrm{C}$, and maintained on a 12:12 light-dark cycle with lights on (100 Lux) at 8 am. Wood shavings and EnviroDry® were used as bedding material. Weaning occurred at 21 days of age. All methods were approved by, and are in agreement with the regulations of the Institutional Animal Use and Care Committee of the University of Groningen. These regulations are consistent with the guidelines for the care and use of laboratory animals as described by the U.S. National Institutes of Health.

Experimental design

After a habituation phase, 2-month-old male (6-8 per line) and female mice (6-8 per line) were subjected to an open- 
field test, elevated plus-maze test, and complex maze learning tests on different days in the order as mentioned. Each experiment was performed during the beginning of the light phase, at a time when the general behavioral activity is rather low (Malisch et al. 2008), and effects may not be dampened by the noise of general behavioral arousal towards the end the light phase or dark phase (van Dijk and Strubbe 2003). Before each behavioral test, animals were brought in their own cage to a dimly illuminated room (10 Lux) adjacent to the experimental room $30 \mathrm{~min}$ prior to the behavioral test to reduce the level of psychological stress associated with the transport. Cage-partners remained in the animal room and were shortly placed in a spare cage with some of their own shavings (with food and water ad libitum available). In the experimental room, the light intensity ranged between 70 and 80 Lux. Each time before testing, the open field, plus maze, and complex maze were rigorously cleaned with soap and water, and investigators always left the room during the test. Behavior was recorded (Sony Handycam), and later analyzed using Eline software (dr F. Maes, University of Groningen).

\section{Open-field behavior}

Explorative and spontaneous locomotor activity were observed in a circular horizontal arena. In this arena ( $1.0 \mathrm{~m}$, height of vertical surrounding wall: $0.4 \mathrm{~m}$ ), concentric circles were depicted at one-third and at twothird of the arena's diameter, dividing the surface into a center, a middle ring and an outer ring (adapted from Walsh and Cummins 1976). At the beginning of each trial, the mouse was placed in the center of the arena.

Mice were tested for $5 \mathrm{~min}$, including $1 \mathrm{~min}$ at the end when a $1-\mathrm{kg}$ brass weight was introduced into the center of the open field to test the animals' exploratory behavior for a novel object. Behavior was recorded and the following traits were determined: percentage of time spent in outer ring, middle ring and center, number of visits into each ring (visit frequency), total number crossings from one ring to the next (crossing frequency), and number of rearings.

\section{Elevated plus-maze}

Anxiety was evaluated using the elevated plus-maze test, which is based on the aversion for open, well-illuminated spaces (Treit et al. 1993). The elevated plus-maze consisted of two open arms and two closed arms facing each other, $40 \mathrm{~cm}$ above the floor. Each arm was $29 \mathrm{~cm}$ long and $5 \mathrm{~cm}$ wide. The closed arms had $15 \mathrm{~cm}$ high walls with a closed top. At the beginning of each trial, the mouse was placed on the central area $(5 \times 5 \mathrm{~cm})$ facing an open arm and allowed to explore the maze for $5 \mathrm{~min}$. The following traits were determined: time spent in open arms and closed arms, time spent in central area, number of visits to open arms and closed arms, and number of total arm entries. An arm entry was counted when the front paws were placed on the arm.

\section{Complex maze}

Spatial learning performance was assessed with a complex maze that was based on the configuration originally developed by Rabinovitch and Rosvold (1951), and adapted for mice. The maze was constructed of a horizontal surface $(25 \times 19 \mathrm{~cm})$, with vertical barriers $(7 \mathrm{~cm}$ high) arranged to form a maze (see Fig. 1). To prevent the mouse from jumping out, the maze was enclosed in a transparent Plexiglas box (which allowed observation of the mouse's behavior).

The day before starting test sessions, mice were once allowed to explore the maze to avoid stress of novelty during maze performance on day 1 . The following procedure was executed. Thirty minutes before the complex maze performance test, one of the animals from a home cage and part of the shavings were transferred to an experimental cage located in a habituation room adjacent to the experimental room. From the habituation room, the mouse inside this experimental cage was brought into the experimental room, where this cage was connected via a Plexiglas tube ( $\varnothing 5 \mathrm{~cm}$, length $17 \mathrm{~cm}$ ) to the maze entry (left hand side in Fig. 1). After the mouse entered the tube towards the maze, a sliding door inside the tube was closed, and the experimental cage was disconnected and reattached to the exit tube on the opposite corner at the right hand side of the maze (see Fig. 1). Then the investigator left the room, and followed the mouse's behavior via a monitor outside the experimental room. Once the mouse found its experimental cage again behind the exit tube, the investigator entered the room and returned the mouse, inside its cage, to the adjacent room where the animal was returned

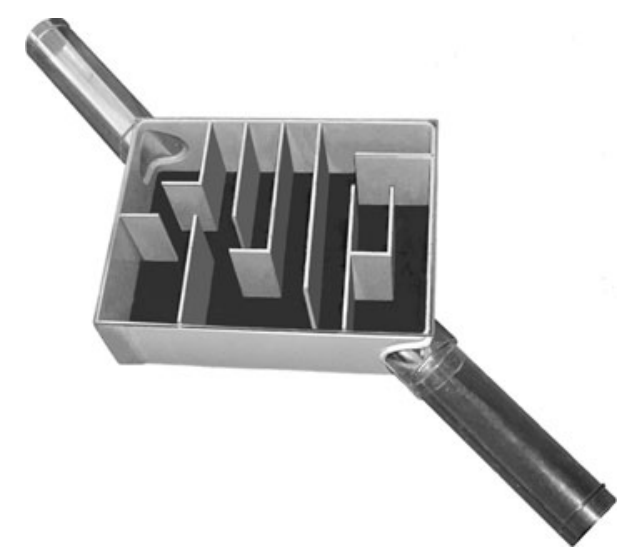

Fig. 1 The complex maze adapted from Rabinovitch and Rosvold (1951), with the entry on the left hand side and the exit on the right 

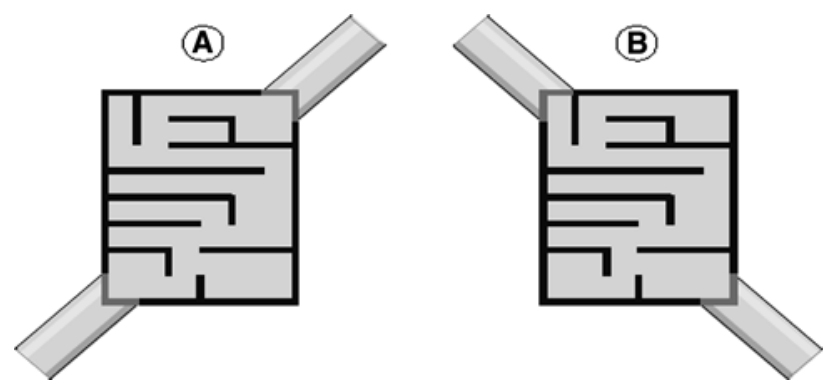

Fig. 2 Configuration of the complex maze during the first 2 days (a), and during the last trial on the third day (b), where the entrance and exit were laterally inverted. Note that the on the third day the mouse bypasses the "new" displaced exit (configuration b) when searching for the "old" exit (configuration a)

to its home cage. On two successive experimental days, mice were subjected to the maze four times a day with sessions $30 \mathrm{~min}$ apart. In all trials, the latency of reaching the exit and the number of errors were scored. On the third day, mice were once tested in the maze, but with the entrance and exit laterally inverted (Fig. 2b). It was assessed whether and how long it took for the mice to reach the "new" displaced exit, and whether they exited the maze directly through the "new" exit, or searched the corner of the old exit first.

\section{Statistical analysis}

Data for open-field and elevated plus maze were analysed with GLM models in SPSS (version 12). Line and sex were added as fixed factors. Further individual comparisons were performed using Tukey's post-hoc tests. In the complex maze analysis, the GLM models for repeated measures were applied. When the entrance and exit of the maze were inverted laterally on the third day, data were further analyzed by two-tailed $t$-tests and Chi-squared test for nominal data. In the latter, we compared the number of mice going directly to the inverted exit and the ones that were still looking at the old position. Results are given as mean$\mathrm{s} \pm \mathrm{SEM}$ and are considered significantly different when $p<0.05$.

\section{Results}

\section{Open field}

During the first 4 min, multivariate analysis including all test variables revealed effects of line $(F(14,116)=3.89$; $p<0.001$ ), but not of sex or of the interaction between line and sex. Specifically, the percentage of time spent in different compartments was significantly influenced by line $(F(2,53)=6.20 ; p=0.004)$; post-hoc analysis revealed that line 8 mice spent significantly more time in the middle ring than line $7(p=0.004)$ and line 2 mice $(p=0.05)$ (Fig. 3, top panel). Furthermore, a line effect was also found in the number of visits in the outer $(F(2,53)=4.89$; $p=0.01)$ and middle rings $(F(2,53)=5.34 ; p=0.008)$. Line 8 had a higher frequency of middle-ring visits than line $2(p=0.01)$, and line 8 had higher frequency of outer$(p=0.01)$ as well and middle-ring $(p=0.04)$ visits than line 7 (Fig. 3, middle panel). The number of rearings also revealed an effect of line $(F(2 ; 53)=14.21 ; p<0.001)$; line 7 had a higher number of rearings than line 2 $(p<0.001)$ and line $8(p<0.001)$ (Fig. 3, lower panel).

Upon introduction of the novel object in the center of the open field (during the last minute), multivariate analysis did not show any significant effects. However, univariate analysis revealed effects of line on the time spent in the center ring $(F(2,53)=4.87 ; p=0.01)$. Line 8 mice spent more time in the center than line $2(p<0.05)$ and line 7 mice $(p=0.01)$. The time spent in the outer ring tended to be influenced by line $(F(2,53)=3.14$; $p=0.05)$; specifically line 8 spent significantly less time in the outer ring than line $7(p=0.05)$.

\section{Plus-maze}

Plus-maze behavior of mice from the different breeding lines is shown in Fig. 4. Multivariate analysis revealed a significant effect of line $(F(12,118)=4.07 ; p<0.001)$. Univariate analysis revealed the following. Firstly, an effect of line was found in the percentage of time spent in the open arms $(F(2,54)=6.12 ; p=0.004)$ and in the closed arms $(F(2,54)=6.46 ; p=0.003)$. Specifically, line 8 mice spent less time in the open arms $(p=0.003)$ and more time in the closed arms than line 2 mice $(p=0.003)$ (Fig. 3, top panel). Secondly, an effect of line was also detected in the number of open arm entries $(F(2,54)=$ $4.25 ; p=0.02)$, closed arm entries $(F(2,54)=10.57$; $p<0.001)$ and central area entries $(F(2,54)=7.23 ; p=$ $0.002)$. Specifically, line 8 mice made fewer entries into the open arms than line $2(p=0.04)$ and line 7 mice $(p=0.04)$; line 7 mice had higher number of entries into closed arms relative to line $2(p<0.001)$ and line 8 $(p=0.008)$ and into the central area relative to line 2 $(p=0.01)$ and line $8(p=0.002)$. A line effect was also found in the percentage of open-arms entries $(F(2,54)=$ $6.92 ; p=0.002)$ and the percentage of closed-arms entries $(F(2,54)=6.92 ; p=0.002)$; i.e., line 8 had smaller percentage of open arms entries than line $2(p=0.002)$, and line 2 had smaller percentage of closed arms entries than line $7(p=0.04)$ and line $8(p=0.002)$ (Fig. 3, bottom panel). The total number of arm entries was also influenced by line $(F(2,54)=6.02 ; p=0.005)$; i.e., line 7 had significantly more total arm entries than line $8(p=0.004)$ and line $2(p=0.06)$. Finally, a sex effect, but no 

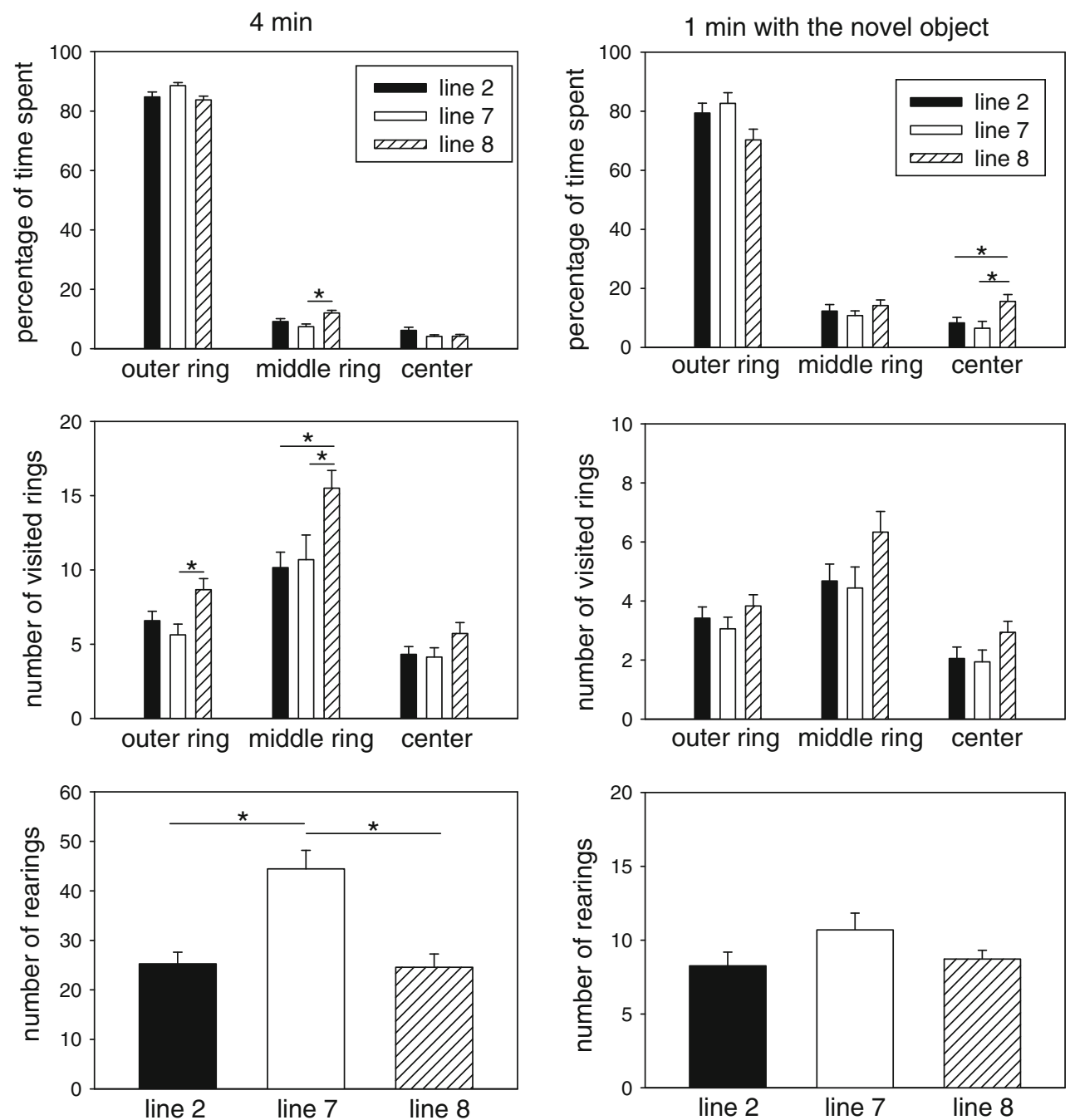

Fig. 3 Open-field behavior of mouse lines 2 (control), 7 (selectively bred for high voluntary wheel running), and 8 (also selected) during the first 4 min (left panels) and during the last minute after which a novel object was introduced in the center of the open field (right

interaction effect, was found in the percentage of time spent in the open $(F(1,43)=4.21 ; p=0.046)$ and closed arms $(F(1,43)=6.30 ; p=0.015)$. Specifically, females spent more time in open arms and less time in closed arms than males (individual data for females and males not shown).

\section{Complex maze}

With GLM repeated-measures analysis, the performance of animals in all groups improved upon training in our complex maze. Repeated task exposure resulted in a decrease of the time spent in the maze to find the exit when observed 4 trials per day for 2 days $(F(7,43)=8.59 ; p<0.001)$ (see Fig. 5). A significant line effect was also found $(F(2,49)=$ $4.15, p=0.02)$, but no sex or line $*$ sex interaction was observed. Post-hoc analysis revealed that line 8 mice took

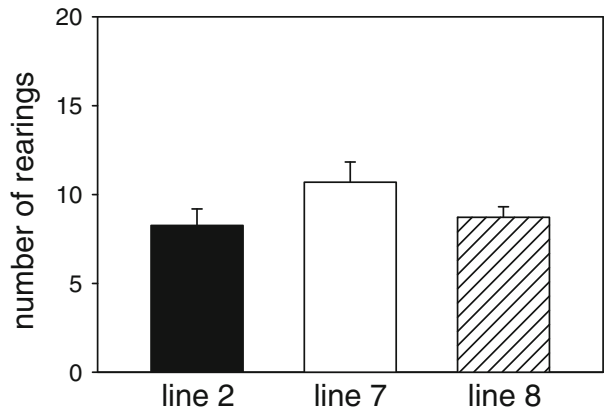

panels). The top panels show the percentage of time the animals spent in the different areas, the middle panels show the number of visits to the different areas, and the lower panels show the total number of rearings. * indicate significant difference between means at $p<0.05$

significantly more time in the maze, particularly on day 2 , to reach the exit than line $2 \mathrm{did}(p=0.02)$.

When the exit and entrance of the maze were displaced laterally, repeated measures within subject analysis revealed that mice needed significantly more time to find the new and correct exit $(F(1,55)=22.53 ; p<0.001)$. Furthermore, interaction effects of time $*$ line $(F(2,55)=3.69 ; p=$ $0.03)$ and time $* \operatorname{sex}(F(1,55)=6.09 ; p=0.02)$, but no interaction of time * line $*$ sex were revealed, meaning that line 7 needed significantly more time to find the new exit, particularly females. This is consistent with the time spent in the maze in this last trial when the maze was displayed laterally, showing an effect of line $(F(2,54)=4.22 ; p=0.02)$; line 7 spent significantly more time to find the correct displaced exit relative to line $2(p=0.02)$ (Fig. 6, upper panel). The number of mistakes did not differ between groups (Fig. 6, middle panel). Furthermore, logistic analysis 

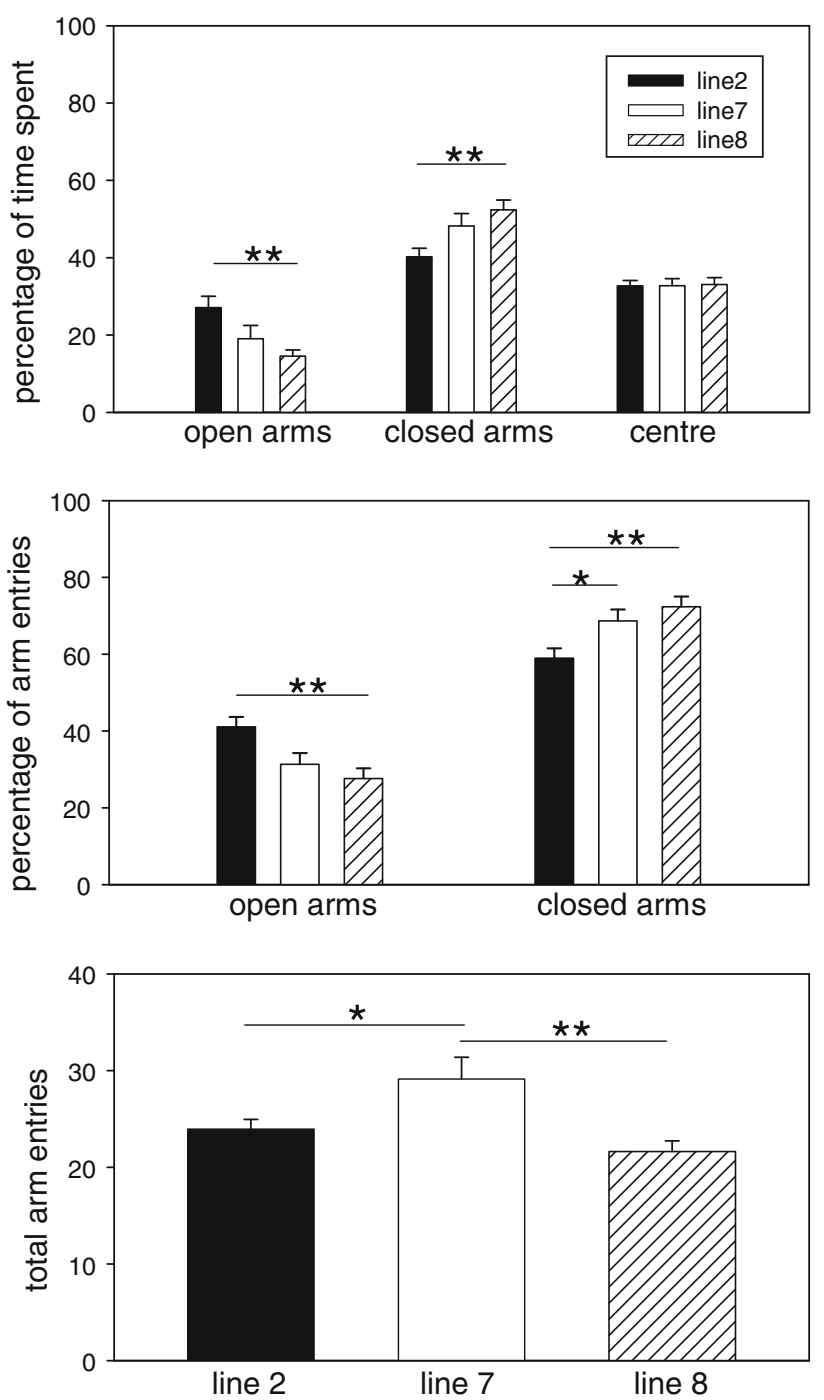

Fig. 4 Plus-maze behavior of mouse lines 2 (control), 7 (selectively bred for high voluntary wheel running), and 8 (also selected). Top panel shows the percentage of time spent in the open arms, closed arms and in the center. Middle panel shows the percentage of arm entries into the open and closed arms. Lower panel shows total arm entries. Asterisks indicate significant difference between means at $p<0.05(*)$, and $p<0.01(* *)$

revealed an effect of line $\left(\chi^{2}(2)=7.61, p<0.05\right)$, but no effect of sex or line $*$ sex interaction in the number of animals for which the first attempt led to the correct exit. Specifically, line 2 animals more frequently chose the new inverted exit than line $7\left(\chi^{2}(1)=7.51, p<0.01\right)$ and line 8 mice $\left(\chi^{2}(1)=7.51, p<0.01\right)$ for their first attempt.

\section{Discussion}

Long-term selective breeding for high voluntary physical activity in animals may alter behavioral traits from certain behavioral domains that could be adaptive for sustaining a high activity level. In the present study, we investigated potential differences in behavioral traits of two lines of mice selectively bred for high voluntary wheel-running activity and a non-selected control line. Outcomes of an open-field test (to asses explorative behavior), a plus-maze test (to assess anxiety levels), and a complex maze test (to assess learning and routine behavior) indeed showed profound differences between mice of the high-activity lines and the control line. However, the magnitude and direction in the shifts of behavior in the high-activity mice relative to controls were not always uniform.

Important for consideration of the results of the present study is the fact that mice were tested in their "sedentary" state and in fact were never given access to running wheels. The reason for this was that previous exposure to wheel running may influence outcomes of behavioral tests (e.g., (Rhodes et al. 2003; Malisch et al. 2009)). Thus, here we deal with animals which normally show different amounts of locomotor behavior in running wheels, but have no possibility to express this behavior. From offspring of this generation used for other purposes, however, we know that the average daily wheel revolutions behavior in line 7 and line 8 mice was, respectively, 2 times and 2.1 times more than that of controls (unpublished results). Even without running wheels, Malisch et al. found that the selected mice have increased spontaneous locomotor behavior assessed with force plates under the cages with activity measured as changes in voltage output from isometric force transducers (Malisch et al. 2008, 2009). Increased spontaneous activity in mice might manifest itself as increased locomotion in the open field, which we scored as "exploratory behavior". Indeed, line 8 mice showed more locomotion and visit frequency towards the middle ring (Fig. 3) than controls. In addition, line 8 showed more exploration in the center when the novel object was placed in the center of the open field. Line 7 mice, however, did not increase locomotion towards the middle ring, but in stead showed almost a doubling of rearing or upright behavior exploring the wall compared to control and line 8 mice. Thus, although expressed differently, both selection lines clearly showed increased "information gathering" behavior in the empty open field. When a novel object was placed in the open field, only line 8 mice showed increased "approach" and "risk-assessment" behavior (Augustsson and Meyerson 2004). The fundamental difference in the latter behavior in line 8 versus line 7 may be explained by a specific behavioral trait that has been distinctly co-selected in line 8. Alternatively, the response in line 8 mice may be secondary to the "horizontal" expression of exploratory behavior, which more likely is followed by "approach" behavior to the novel object than the "vertical" expression of exploratory behavior displayed by line 7. Either way, 


\section{Day 1}
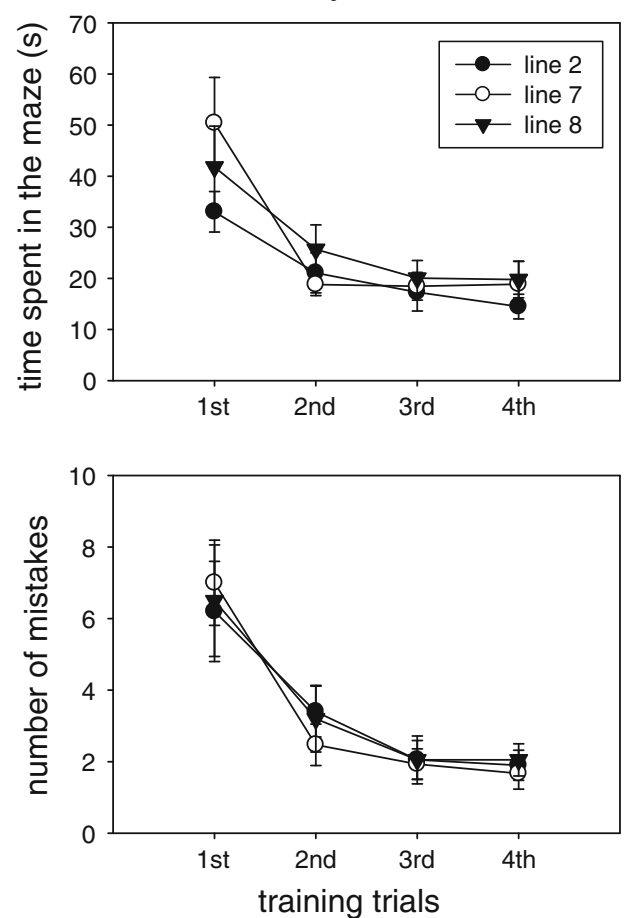

Fig. 5 Complex maze behavior of mouse lines 2 (control), 7 (selected), and 8 (selected) on first day (left panels), and on the second day (right panels). Top panels show the duration in the maze

selection of voluntary wheel running behavior in separate mouse lines does not necessarily lead to completely similar expression of other behavioral traits.

In the plus-maze test, activity selected mice and in particular of line 8 (with line 7 mice as the intermediate phenotype) spent less time in the open arms than the control mice, which is indicative of higher anxiety levels in selected than control mice. This seems incongruent with the findings in the "surveyable" open field tests, where line 7 and 8 mice displayed more exploratory behavior, and moreover with line 8 mice showing more risk-assessment towards the novel object placed in the center. In the complex maze test, all mice showed learning performance over time. Over the course of several trials, we did not observe that activity-selected mice learned faster or slower than controls. This is consistent with the findings by Rhodes et al., showing no differences in learning capabilities of selected mice in a Morris water maze (Rhodes et al. 2003) compared to controls when they did not have access to running wheels. However, the selected mice from line 8 , needed slightly more time to find the exit, but without making more mistakes than controls. Perhaps line 8 mice are more cautious and slower in their travel paths in "non-surveyable" environments, which may fit the higher anxiety levels of these animals in the plus-maze test. When the exit of the maze was displaced on day 3 , selected mice (lines 7 and 8) spent longer time in the maze searching for the
Day 2
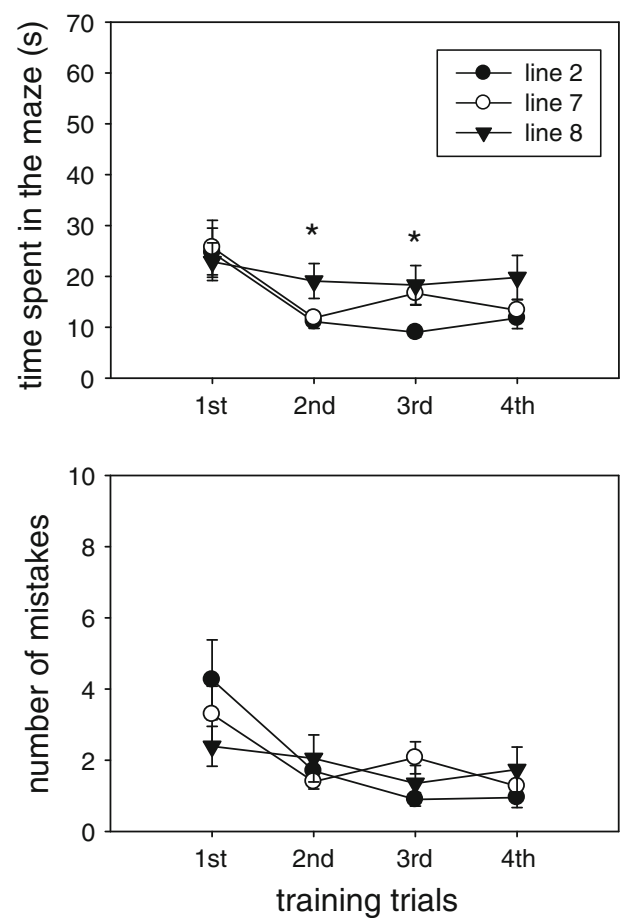

to find the exit, and the lower panels show the number of mistakes the mice made. * indicate significant difference between means at $p<0.05$

new exit, and they more frequently visited the original exit relative to controls. Assuming that there are no differences in visual or odor detection among lines (i.e., they all bypassed the tube directly connected to their home cage on their way to the old exit), this points to a more routine-like behavior in both selected lines of mice compared to controls, irrespective of sex.

Based on the present results, it may be concluded that selection for increased wheel-running behavior has caused changes in a number of behavioral traits. Perhaps the increased routine-like behavior of selected mice may help to sustain increased "monotonous" physical activity, such as wheel running behavior. But what about the other behaviors, such as cautiousness, anxiety, and exploratory behavior? From an evolutionary standpoint, it may be speculated that individuals that display a high level of physical activity have an advantage in habitats that require relatively large home ranges or territories (for example, for food and/or partner seeking), provided that they are cautious, exploratory, and stick to routines at the same time. In other words, individuals ranging over relatively large areas have an elevated risk of predation, which could be compensated by appropriate behaviors (Clobert et al. 2000). Correlated responses to selection can also occur because of pleiotropic gene action, which may be especially common for behavioral traits. In this event, one needs to differentiate 

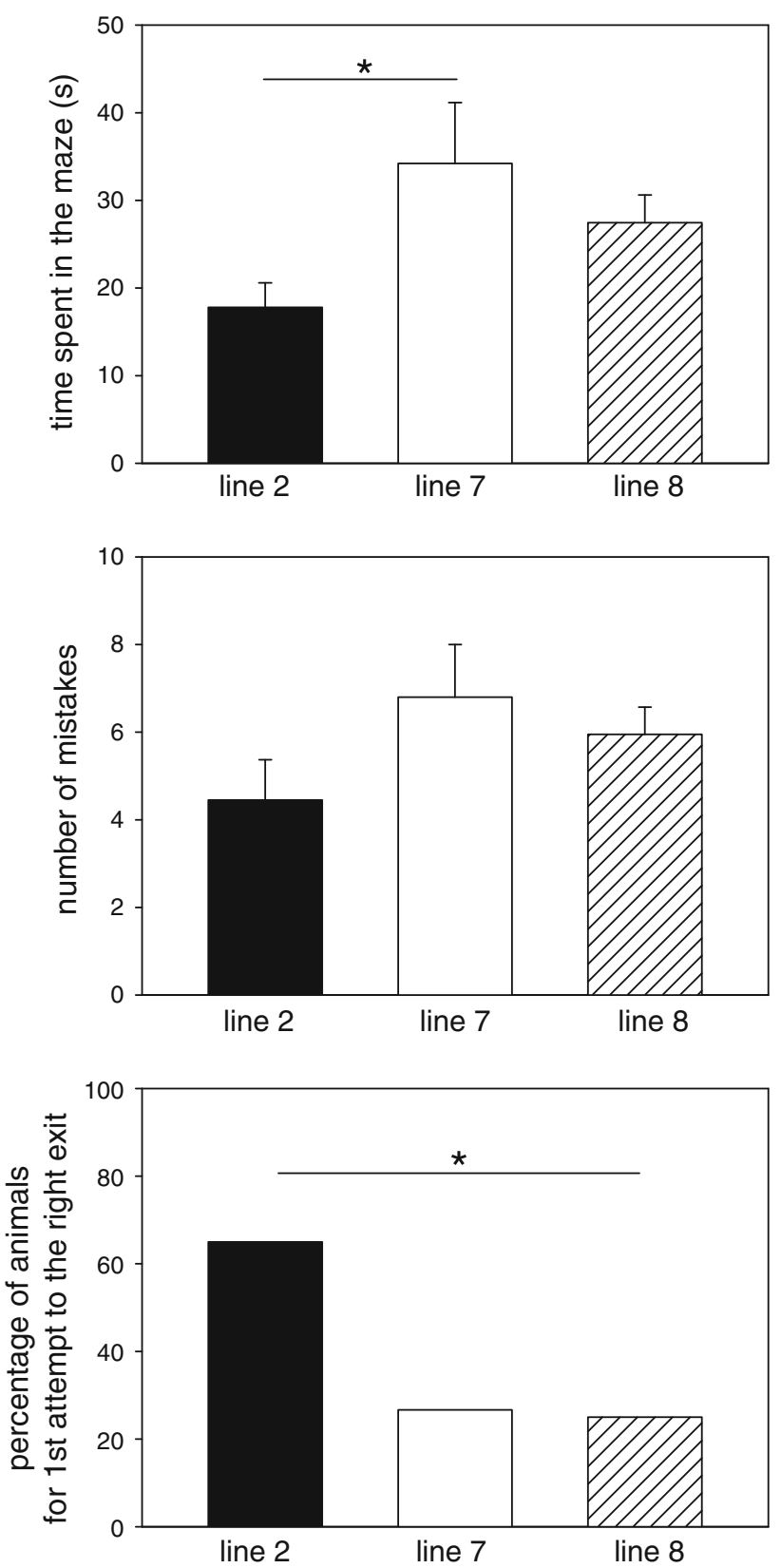

Fig. 6 Complex maze behavior of mouse lines 2 (control), 7 (selected), and 8 (selected) during the final trial on the third day during which the entrance and exit were inverted laterally. Top panel shows the time spent in the maze. The middle panel shows the number of mistakes the mice make in the maze, and the lower panel shows the percentage of mice going directly at the first attempt to the new inverted exit. * Indicate significant difference between means at $p<0.05$

between selection that may act to favor particular combinations of traits (i.e., caution with wide ranging, but also potentially neuroendocrine control pathways that allow increased fuel oxidation to facilitate exercise (Vaanholt et al. 2008)). Secondly, the response to selection may "drag along" any genetically correlated trait in the population at that time (see for example (Bult and Lynch 2000)), whether that genetic correlation is caused by linkage or pleiotropy. In the latter case, these interactions could be adaptive or even maladaptive (Malisch et al. 2008, 2009). It would be of interest to test the relevance of any of these interactions and potential trade-offs in mice living in natural habitats (Benus et al. 1991).

It may seem difficult to combine the aforementioned antagonistic behaviors from a neurobiological standpoint. In their transient hypofrontality hypothesis (Dietrich 2003), Dietrich et al. suggested that there is a temporary inhibition of neural activity in the prefrontal lobe during monotonous, automated movements, such as running (Dietrich and Sparling 2004). At the same time, when neuronal activity in the prefrontal lobes becomes reduced, the basal ganglia are being activated, which control routine behavior (Dietrich and Sparling 2004; Graybiel 2008). It may be speculated that mice from the selected lines have a higher capacity of re-allocating neuronal activity from prefrontal cortical regions to the basal ganglia during exercise, which may help them to sustain this behavior. This may provide a neurobiological explanation for the observation that selected animals, after extensive maze-learning, visited the former "habituated" exit in the complex maze. In a novel environment, however, where the selected mice are faced with uncertainty (such as in the open field), this switch between neuronal activity from prefrontal cortex to basal ganglia probably does not occur. If anything, the selected mice show increased curiosity and exploration in a novel environment, which reduces uncertainty and vigilance (Dember and Earl 1957; Berlyne 1966). It may be speculated that in the natural habitat, where natural resources sometimes become transiently smaller and/or predation pressure is increased, the behavioral characteristics of increased voluntary activity associated with-or perhaps causal to-curiosity and exploration may be adaptive and may increase the chances of survival.

Acknowledgments This work was supported primarily by a Career Development Grant from the Dutch Diabetes Foundation (to G. van Dijk). Additional support was provided by grants from the U.S. National Science Foundation (to T. Garland), most recently IOB0543429, and the Hungarian OTKA grant (to C. Nyakas).

Open Access This article is distributed under the terms of the Creative Commons Attribution Noncommercial License which permits any noncommercial use, distribution, and reproduction in any medium, provided the original author(s) and source are credited.

\section{References}

Antunes HK, Stella SG, Santos RF, Bueno OF, de Mello MT (2005) Depression, anxiety and quality of life scores in seniors after an endurance exercise program. Rev Bras Psiquiatr 27:266-271

Augustsson H, Meyerson BJ (2004) Exploration and risk assessment: a comparative study of male house mice (Mus musculus musculus) and two laboratory strains. Physiol Behav 81:685-698 
Bell RR, Spencer MJ, Sherriff JL (1995) Diet-induced obesity in mice can be treated without energy restriction using exercise and/or a low fat diet. J Nutr 125:2356-2363

Benus RF, Bohus B, Koolhaas JM, van Oortmerssen GA (1991) Heritable variation for aggression as a reflection of individual coping strategies. Experientia 47:1008-1019

Berlyne DE (1966) Curiosity and exploration. Science 153:25-33

Bi S, Scott KA, Hyun J, Ladenheim EE, Moran TH (2005) Running wheel activity prevents hyperphagia and obesity in Otsuka longevans Tokushima Fatty rats: role of hypothalamic signaling. Endocrinology 146:1676-1685

Brock CM, King DS, Wofford MR, Harrell TK (2005) Exercise, insulin resistance, and hypertension: a complex relationship. Metab Syndr Relat Disord 3:60-65

Bronikowski AM, Carter PA, Swallow JG, Girard IA, Rhodes JS et al (2001) Open-field behavior of house mice selectively bred for high voluntary wheel-running. Behav Genet 31:309-316

Bult A, Lynch CB (2000) Breaking through artificial selection limits of an adaptive behavior in mice and the consequences for correlated responses. Behav Genet 30:193-206

Clobert J, Opplige A, Sorci G, Ernande B, Swallow JG et al (2000) Trade-offs in phenotypic traits: endurance at birth, growth, survival, perdation, and susceptibility to parasitism in a lizard, Lacerta vivipara. Funct Ecol 4:675-684

Dember WN, Earl RW (1957) Analysis of exploratory, manipulatory, and curiosity behaviors. Psychol Rev 64:91-96

Dey S (1994) Physical exercise as a novel antidepressant agent: possible role of serotonin receptor subtypes. Physiol Behav 55:323-329

Dietrich A (2003) Functional neuroanatomy of altered states of consciousness: the transient hypofrontality hypothesis. Conscious Cogn 12:231-256

Dietrich A, McDaniel WF (2004) Endocannabinoids and exercise. Br J Sports Med 38:536-541

Dietrich A, Sparling PB (2004) Endurance exercise selectively impairs prefrontal-dependent cognition. Brain Cogn 55:516-524

Gammie SC, Hasen NS, Rhodes JS, Girard I, Garland T Jr (2003) Predatory aggression, but not maternal or intermale aggression, is associated with high voluntary wheel-running behavior in mice. Horm Behav 44:209-221

Garland T Jr (2001) Phylogenetic comparison and artificial selection. Two approaches in evolutionary physiology. Adv Exp Med Biol 502:107-132

Garland T Jr, Morgan MT, Swallow JG, Rhodes JS, Girard I et al (2002) Evolution of a small-muscle polymorphism in lines of house mice selected for high activity levels. Evolution 56:1267-1275

Girard I, McAleer MW, Rhodes JS, Garland T Jr (2001) Selection for high voluntary wheel-running increases speed and intermittency in house mice (Mus domesticus). J Exp Biol 204:4311-4320

Graybiel AM (2008) Habits, rituals, and the evaluative brain. Annu Rev Neurosci 31:359-387

Greenwood BN, Strong PV, Dorey AA, Fleshner M (2007) Therapeutic effects of exercise: wheel running reverses stress-induced interference with shuttle box escape. Behav Neurosci 121: 992-1000

Hartmann J, Garland T Jr, Hannon RM, Kelly SA, Munoz G et al (2008) Fine mapping of "mini-muscle", a recessive mutation causing reduced hindlimb muscle mass in mice. J Hered 99: 679-687
Hayes C, Kriska A (2008) Role of physical activity in diabetes management and prevention. J Am Diet Assoc 108:S19-S23

Hillman CH, Erickson KI, Kramer AF (2008) Be smart, exercise your heart: exercise effects on brain and cognition. Nat Rev Neurosci 9:58-65

Kligman EW, Pepin E (1992) Prescribing physical activity for older patients. Geriatrics 47:33-44, 47

Koteja P, Garland T Jr, Sax JK, Swallow JG, Carter PA (1999) Behaviour of house mice artificially selected for high levels of voluntary wheel running. Anim Behav 58:1307-1318

Levin BE, Dunn-Meynell AA (2004) Chronic exercise lowers the defended body weight gain and adiposity in diet-induced obese rats. Am J Physiol Regul Integr Comp Physiol 286:R771-R778

Malisch JL, Breuner CW, Gomes FR, Chappell MA, Garland T Jr (2008) Circadian pattern of total and free corticosterone concentrations, corticosteroid-binding globulin, and physical activity in mice selectively bred for high voluntary wheelrunning behavior. Gen Comp Endocrinol 156:210-217

Malisch JL, Breuner CW, Kolb EM, Wada H, Hannon RM et al (2009) Behavioral despair and home-cage activity in mice with chronically elevated baseline corticosterone concentrations. Behav Genet 39:192-201

Patterson CM, Levin BE (2008) Role of exercise in the central regulation of energy homeostasis and in the prevention of obesity. Neuroendocrinology 87:65-70

Pietropaolo S, Sun Y, Li R, Brana C, Feldon J et al (2008) The impact of voluntary exercise on mental health in rodents: a neuroplasticity perspective. Behav Brain Res 192:42-60

Rabinovitch MS, Rosvold HE (1951) A closed-field intelligence test for rats. Can J Psychol 5:122-128

Rhodes RE, Smith NE (2006) Personality correlates of physical activity: a review and meta-analysis. $\mathrm{Br} \mathrm{J}$ Sports Med 40: 958-965

Rhodes JS, Hosack GR, Girard I, Kelley AE, Mitchell GS et al (2001) Differential sensitivity to acute administration of cocaine, GBR 12909 , and fluoxetine in mice selectively bred for hyperactive wheel-running behavior. Psychopharmacology (Berl) 158: $120-131$

Rhodes JS, Van PH, Jeffrey S, Girard I, Mitchell GS et al (2003) Exercise increases hippocampal neurogenesis to high levels but does not improve spatial learning in mice bred for increased voluntary wheel running. Behav Neurosci 117:1006-1016

Swallow JG, Carter PA, Garland T Jr (1998) Artificial selection for increased wheel-running behavior in house mice. Behav Genet 28:227-237

Treit D, Menard J, Royan C (1993) Anxiogenic stimuli in the elevated plus-maze. Pharmacol Biochem Behav 44:463-469

Vaanholt LM, Jonas I, Doornbos M, Schubert KA, Nyakas C et al (2008) Metabolic and behavioral responses to high-fat feeding in mice selectively bred for high wheel-running activity 1 . Int $\mathbf{J}$ Obes (Lond) 32:1566-1575

van Dijk G, Strubbe JH (2003) Time-dependent effects of neuropeptide $\mathrm{Y}$ infusion in the paraventricular hypothalamus on ingestive and associated behaviors in rats. Physiol Behav 79:575-580

van Praag H, Christie BR, Sejnowski TJ, Gage FH (1999) Running enhances neurogenesis, learning, and long-term potentiation in mice. Proc Natl Acad Sci USA 96:13427-13431

Walsh RN, Cummins RA (1976) The open-field test: a critical review. Psychol Bull 83:482-504 